Human Impact on the Environment 
Sergey Govorushko

\section{Human Impact on the Environment}

An Illustrated World Atlas

黛 Springer 


\author{
Sergey Govorushko \\ Pacific Geographical Institute \\ Far Eastern Federal University \\ Vladivostok \\ Russia
}

ISBN 978-3-319-24955-1

ISBN 978-3-319-24957-5 (eBook)

DOI 10.1007/978-3-319-24957-5

Library of Congress Control Number: 2015951778

Springer Cham Heidelberg New York Dordrecht London

(C) Springer International Publishing Switzerland 2016

This work is subject to copyright. All rights are reserved by the Publisher, whether the whole or part of the material is concerned, specifically the rights of translation, reprinting, reuse of illustrations, recitation, broadcasting, reproduction on microfilms or in any other physical way, and transmission or information storage and retrieval, electronic adaptation, computer software, or by similar or dissimilar methodology now known or hereafter developed.

The use of general descriptive names, registered names, trademarks, service marks, etc. in this publication does not imply, even in the absence of a specific statement, that such names are exempt from the relevant protective laws and regulations and therefore free for general use.

The publisher, the authors and the editors are safe to assume that the advice and information in this book are believed to be true and accurate at the date of publication. Neither the publisher nor the authors or the editors give a warranty, express or implied, with respect to the material contained herein or for any errors or omissions that may have been made.

Printed on acid-free paper

Springer International Publishing AG Switzerland is part of Springer Science+Business Media (www.springer.com) 


\section{Preface}

This book has a dual purpose. On the one hand, it is a geographic atlas, a collection of geographical maps united by a common theme. In this case, the theme is human impacts on nature. All of the maps in this atlas show either distribution of different kinds of human activities or geographical aspects of their effects on natural components. As for territorial coverage, it is an atlas of the world because all the aspects of human impact on the environment are considered on a global basis.

On the other hand, this volume is a reference book. It contains short descriptions of the various kinds of human activity and their effects on specific natural components. It reflects scientific knowledge on these problems as it stood during the late twentieth to early twenty-first century. The extremely limited volume of text allowed us to provide only minimal necessary information. More detailed information can be found in the references listed at the end of each chapter.

At the same time, this volume is an illustrated atlas, meaning that text and maps are accompanied by photographs showing specific examples of human effects on the environment. As the saying goes, "One picture is worth a thousand words". In the atlas, there are 300 photographs taken in 70 countries and all oceans.

As to the sources, they can be divided into three categories: (1) some citizens of different countries - chiefly, scientific associates who sent me the needed illustrations in the form of slides, photographs, or separate electronic files; (2) some organizations; and (3) sites of different international, national, and local organizations. I am grateful to the authors and organizations granting permissions for the use of the photographs in this book. It seems to me sometimes that collecting permissions was more difficult than writing the text of the book. Lists of copyright holders for maps and photographs are given in an appendix.

The book also includes about 65 maps. They were obtained for the atlas in a variety of ways: (1) maps found in different sources (books, articles, Internet sites); (2) maps synthesized on basis of two, three, and more sources; and (3) maps prepared by the author specifically for this book. In this case, a search of list of objects was carried out at first, the coordinates were determined, and, after that, the objects were automatically plotted on the map using the program ArcGIS for 
Desktop. All of maps in the atlas are presented in the same projection (Robinson projection).

The author wishes to express his gratitude to Academician P.Ya. Baklanov, Director of the Pacific Geographical Institute, FEB of RAS (Far-Eastern Branch of the Russian Academy of Sciences), for every possible support over many years in conducting the investigations.

The support and assistance of current and former colleagues at the Pacific Geographical Institute are also gratefully acknowledged; included are Mr. V.B. Primak, Dr. S.M. Krasnopeev, Prof. A.M. Panichev, Dr. V.V. Aramilev, Prof. A.V. Moshkov, Mr. A.V. Vlasov, and Mr. V.A. Solkin.

Numerous colleagues from Russia have also contributed indirectly to this book, including Mr. V.A. Kantor, Prof. S.P. Gorshkov (Moscow State University, Moscow), Prof. S.A. Bulanov, Dr. E.V. Trofimova, Prof. A.A. Tishkov (all from the Institute of Geography, Moscow), Ms. E.I. Udilova (Greenpeace/Russia, Moscow), Dr. M.V. Khotuleva (Ecoline EA Centre, Moscow, Russia), Mr. E.V. Kovalev, Ms. L.O. Kudryavtseva, Mr. A.A. Lapin, and others.

The author has had the unique opportunity of becoming acquainted and collaborating with numerous international colleagues. Of particular note are Dr. I. Kelman (Centre for International Climate and Environment Research, Oslo, Norway), Prof. C. Tisdell (University of Queensland, Brisbane, Australia), Prof. H.J. Walker (Louisiana State University, United States), Dr. S.F. Trush (National Institute of Water and Atmospheric Research, Hamilton, New Zealand), and Prof. B. Braun (Geographical Institute of Köln University, Germany).

Of major importance to the author are the positive attitude and helpfulness of Ms. L.P. Slavinskaya for assistance in preparation of the manuscript for publication, and Ms. E.V. Oleinikova for preparation of electronic versions of maps.

Special thanks to Ms. D.M. Miller (Boulder, Colorado, USA) for close editing of the manuscript and her persistence in overcoming differences between the Russian and English, which, as I hope, allowed the book to become clearer for the Western reader. The author would like to thank the translator, V.M. Karpets (Pacific Geographical Institute, Vladivostok, Russia).

The author will be very grateful to all who, after discovering errors, uncertainties, etc., in the book, send information concerning them to me at sgovor@tig. dvo.ru. In addition, e-mailed photographs illustrating impacts of humanity on the environment also would be helpful. 


\section{Contents}

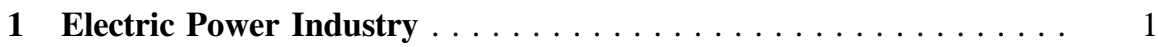

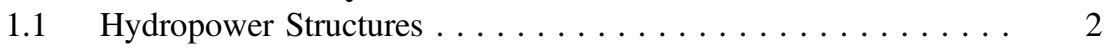

1.2 Thermal Power Structures . . . . . . . . . . . . . . . . . 11

$1.3 \quad$ Nuclear Power Plants . . . . . . . . . . . . . . . . . . . . . . . 15

1.4 Non-traditional or Alternative Power Structures . . . . . . . . . . . . . . 20

1.4.1 Solar Power Structures . . . . . . . . . . . . . . . . 20

1.4.2 Wind Power Structures . . . . . . . . . . . . . 27

1.4 .3 Geothermal Power Structures. . . . . . . . . . . . . . 31

1.4 .4 Use of Oceanic Energy . . . . . . . . . . . . . 34

1.4.5 Electricity Production from Biomass. . . . . . . . . 45

References ....................... 50

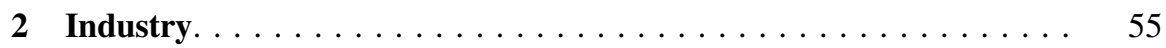

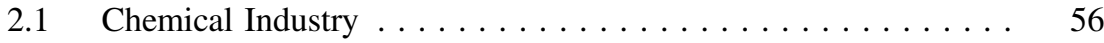

2.1 .1 Petrochemical Industry . . . . . . . . . . . . . 57

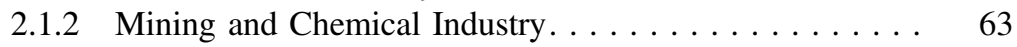

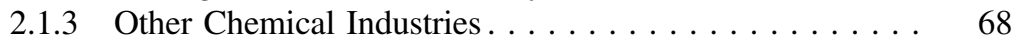

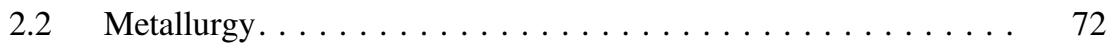

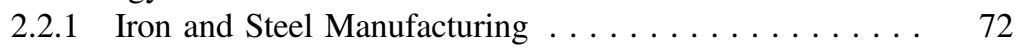

2.2.2 Non-ferrous Metal Manufacturing ... . . . . . . . 75

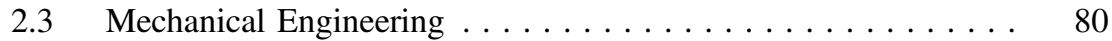

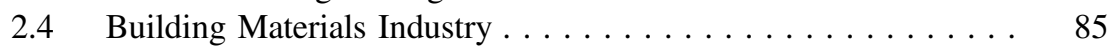

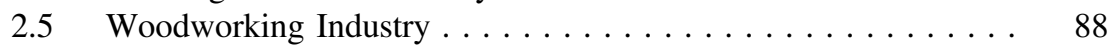

2.6 Wood Pulp and Paper Industry. . . . . . . . . . . . . . . . 92

$2.7 \quad$ Light Industry . . . . . . . . . . . . . . . . . . . . . . . . . . . . . . . . 96

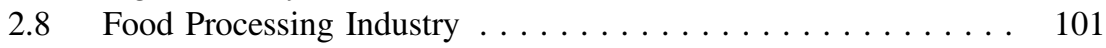

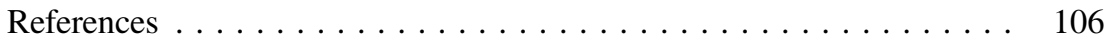

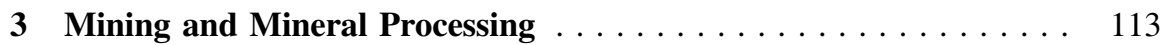

3.1 Opencast Mines . . . . . . . . . . . . . . . . . . . . . . . . . . . . . . . 113

3.2 Underground Mines . . . . . . . . . . . . . . . . . . . . . . . 120

3.3 Drag and Hydraulic Extraction of Deposits . . . . . . . . . . . 124 


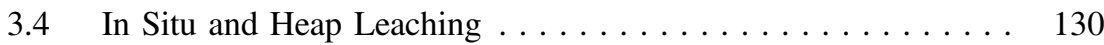

3.5 Oil and Gas Development ................... 133

3.5.1 Land Oil and Gas Development. . . . . . . . . . . . . 133

3.5.2 Sea Bottom Oil and Gas Development . . . . . . . . . 138

3.5.3 Extraction of Shale Oil and Shale Gas . . . . . . . . 143

References ............................. 147

4 Agriculture and Forestry $\ldots \ldots \ldots \ldots \ldots \ldots \ldots \ldots \ldots \ldots \ldots$

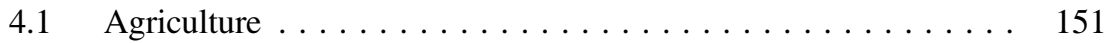

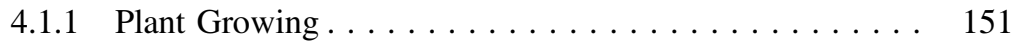

4.1 .2 Animal Husbandry . . . . . . . . . . . . . . . . . . . . 162

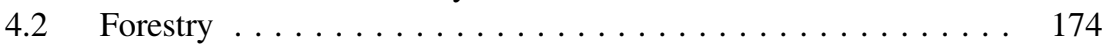

4.2.1 Timber Processing . . . . . . . . . . . . . . . . 174

4.2.2 Reforestation and Plantation Development. . . . . . . . . 185

References .......................... 188

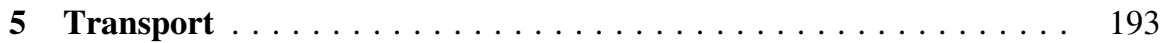

$5.1 \quad$ Automobile Transport . . . . . . . . . . . . . . . . . . . 193

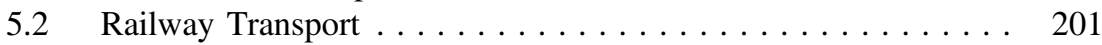

5.3 Pipeline Transport . . . . . . . . . . . . . . . . . . 209

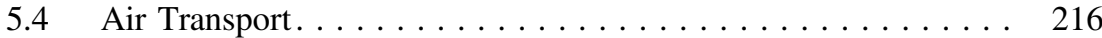

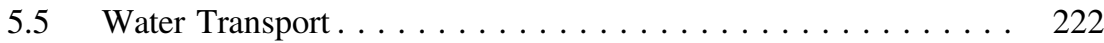

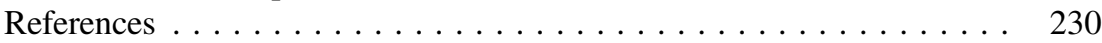

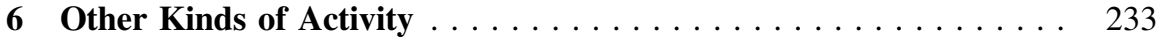

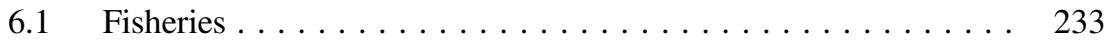

6.2 Aquaculture........................ 244

6.3 Hunting. . . . . . . . . . . . . . . . . . . . . 250

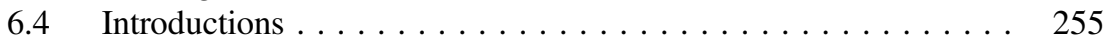

6.5 Water Transfers . . . . . . . . . . . . . . . . . . . . . 259

6.6 Housing and Communal Services. . . . . . . . . . . . . . 264

6.7 Power Transmission and Communication Lines . . . . . . . . . . 272

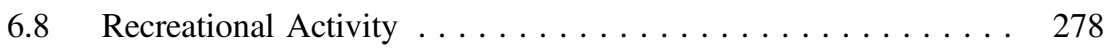

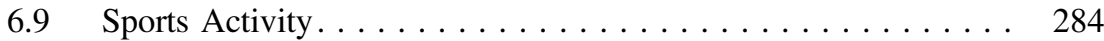

6.10 Military Activity . . . . . . . . . . . . . . . . . . 291

6.11 Space Exploration . . . . . . . . . . . . . . . . . . . . . . 297

6.12 Health and Veterinary Services $\ldots \ldots \ldots \ldots \ldots \ldots \ldots . \ldots \ldots$

6.13 Ritual Activity . . . . . . . . . . . . . . . . . . . . . . . . . 304

References ........................... 311

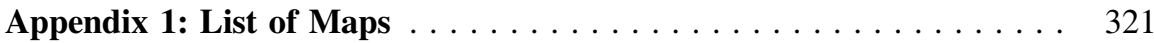

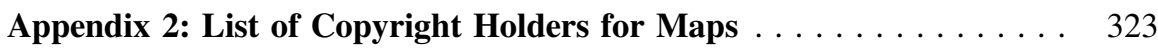


Appendix 3: List of Photos and Their Copyright Holders . . . . . . . . 325

Appendix 4: List of Copyright Holders for Photos . . . . . . . . . . . 333

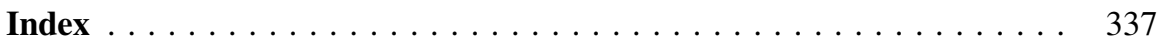




\section{About the Author}

Sergey Govorushko is a chief research scholar at the Pacific Geographical Institute, Russian Academy of Sciences (Vladivostok, Russia). He is also professor at the Far Eastern Federal University (Vladivostok). His research activities focus on the interaction between humanity and the environment, including the impact of natural processes on humanity; the impact of humanity on the environment; and assessment of the interaction (environmental impact assessment, environmental audit, etc.). He has authored ten and co-authored 14 monographs. 


\section{Introduction}

The effects of society on nature began when people first appeared and have a long history. At the early stages of the survival of the human race, the human population was relatively small, and the impact of people on nature was minimal. The situation has changed since people embraced the use of fire more than a hundred thousand years ago.

At the beginning, humans cleared forests with the aid of fire in the course of bushmeat hunting. Later on (8000-3000 BC), forests were cleared with the aid of fire for the purposes of agriculture and military operations (at first in the course of conflicts between tribes, and then between states) rather than hunting. The slash-and-burn system resulted in one of the most essential environmental consequences: the desertification of 2 billion ha of fertile lands, which is greater than the area of presently cultivated lands.

The distribution of different kinds of human activities in $1000 \mathrm{BC}$-i.e., about 3000 years ago - is shown in Fig. 1. The numbers indicate the following:

America: (1) Arctic marine mammal hunters; (2) Subarctic forest hunter-gatherers; (3) North American Pacific foraging, hunting, and fishing peoples; (4) Plateau fishers and hunter-gatherers; (5) Desert hunter-gatherers; (6) Plains bison hunters; (7) Poverty Point culture; (8) Eastern North American woodland hunter-gatherers; (9) Maize farmers; (10) Olmec civilization; (11) Caribbean hunter-gatherers; (12) Manioc farmers (replacing hunter-gatherers); (13) Chorrera culture; (14) El Paraiso culture; (15) Amazon forest hunter-gatherers; (16) Chinchoros culture; (17) Savanna hunter-gatherers; (18) Shellfish gatherers; (19) Andean hunter-gatherers; (20) Pampas cultures; and (21) Patagonian shellfish and marine mammal hunters.

Eurasia: (1) Saami; (2) Finno-Ugric taiga hunter-gatherers; (3) Paleo-Siberian taiga hunter-gatherers; (4) Arctic marine mammal hunters; (5) N. European Bronze Age cultures; (6) Karasuk culture (transhumant pastoralist chiefdoms); (7) Proto-Altaic pastoralists; (8) Urnfield cultures; (9) Cimmerians; (10) Celtiberians; (11) Illyrians; (12) Thrace; (13) Greeks; (14) Phrygians; (15) Hittites; (16) Urartu; (17) Iranian pastoralists; (18) Tibetans (transhumant pastoralists); (19) Sinic peoples; (20) Koreans; (21) Ainu; (22) Levantine Kingdoms; (23) Aramaeans; (24) Elam; 


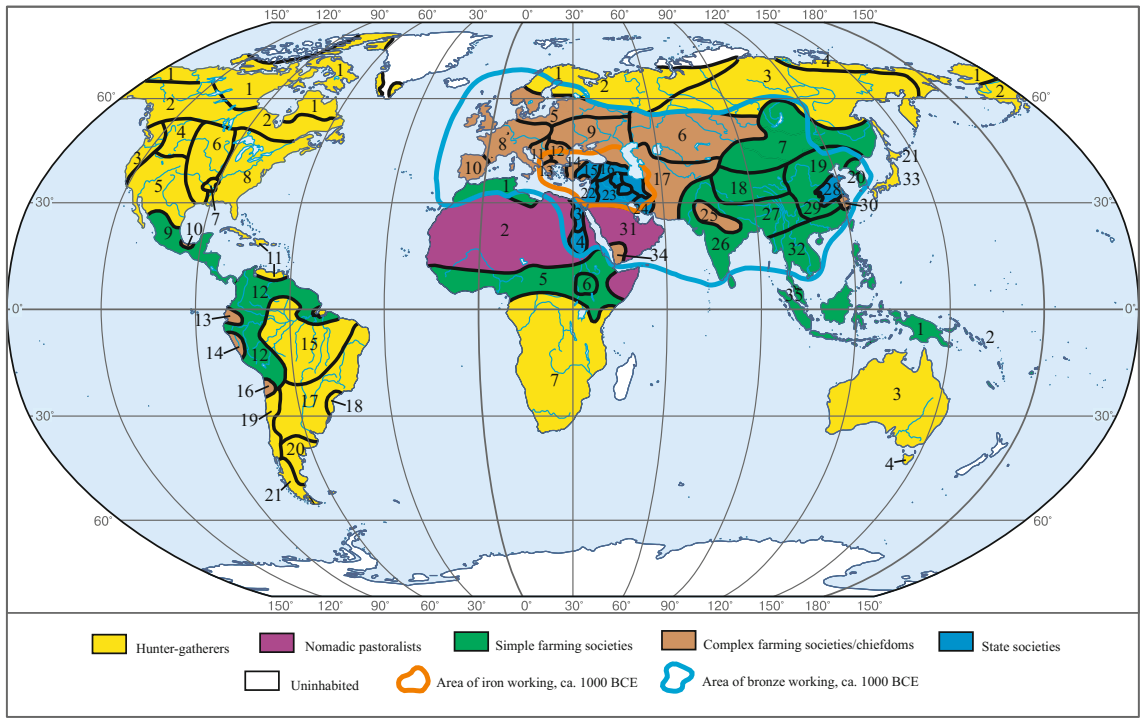

Fig. 1 The world in 1000 BCE (http://en.wikipedia.org/wiki/File:World_1000_BCE.png) [CC BY 2.5 (http://creativecommons.org/licenses/by/2.5)], via Wikimedia Commons

(25) Vedic Aryans; (26) Dravidians; (27) Burmese; (28) Zhou; (29) Thais; (30) Wu; (31) Arabian pastoral nomads; (32) Austro-Asiatic rice farmers; (33) Late Jomon culture; (34) Saba; and (35) Austronesians.

Africa: (1) Berbers; (2) Saharan pastoral nomads; (3) Egypt; (4) Kush; (5) West African cereal farmers; (6) Ethiopian highland farmers; and (7) Khoisan.

Australia and Oceania: (1) Papuan Neolithic farmers; (2) Lapita culture (proto-Polynesians); (3) Australian Aboriginal hunter-gatherers; (4) Tasmanian hunter-gatherers.

Three thousand years ago, the world's population was approximately 50 million people. Naturally, hunting, gathering, and primitive agriculture and livestock farming prevailed in those days. However, in the most developed civilizations, the spectrum of activities was much wider. In some cases, we may speak of housing and communal services.

For example, in the early third millennium BC in Mohenjo Daro, the largest ancient city of the Indus River valley (within the territory of the present-day Pakistan), each house had a canal for discharge of sewage into large main channels. The first waterworks also emerged many millenniums ago. For example, a permanent system of plated pipelines arranged on slopes for providing gravity flow of water existed in ancient Iran 3000 years ago. The water was provided at the expense of groundwater. At that time, water supply lines were also used in the interfluves of the Tigris and the Euphrates Rivers and in the valleys of the Nile and Indus.

Diversion of runoff was also used at that time. For example, an efficient system of drainage-irrigation channels within the Euphrates River basin (south 
Mesopotamia) was created as early as the middle of the fourth millennium BC. It consisted of channels, floodgates, dams surrounding the fields, and shadoofs. Using each of them, one can lift about $2 \mathrm{t}$ of water an hour time to a height of $6 \mathrm{~m}$.

At that time, a primitive cement was already produced in Egypt, while burnt loam bricks were used in the above-mentioned Mohenjo Daro. The oldest known dam has been dated at $3000 \mathrm{BC}$. It was situated within $100 \mathrm{~km}$ of Amman (today's Jordan); it was a stone wall $4.5 \mathrm{~m}$ high and $1 \mathrm{~m}$ thick. According to data from archaeological finds, shipbuilding was used 7200 years ago.

However, technological development has made a gigantic step forward over the last few millenniums. A vast number of new kinds of activities have developed, and industrialization and scientific-technological progress have intensified environmental destruction. On the one hand, the development of industry and its infrastructure required additional destruction of natural ecosystems; on the other hand, a new kind of the impact on the environment and on humans has been seenpollution of natural constituents by anthropogenic wastes and their effects on living organisms.

Human influences on the environment have reached critical scales, and the existence of a global ecological crisis is generally recognized. Some idea of this crisis is given by this atlas. 